\title{
AS IMPLICAÇÕES DO RECONHECIMENTO DA CONDIÇÃO DE REFUGIADO PARA OS VENEZUELANOS
}

\author{
The implications of recognition of the refugee condition for Venezuelans \\ Las implicaciones del reconocimiento de la condición de refugiado para los \\ venezolanos
}

\author{
Francielle Vascotto Folle \\ Nathália Alves de Oliveira** \\ César Augusto Silva da Silva***
}

\begin{abstract}
*Mestranda em Fronteiras e Direitos Humanos na Universidade Federal da Grande Dourados - franciellevascottofolle@hotmail.com.br ** Mestranda em Fronteiras e Direitos Humanos da Universidade Federal da Grande Dourados - nathalia_alvesoliveira@hotmail..com

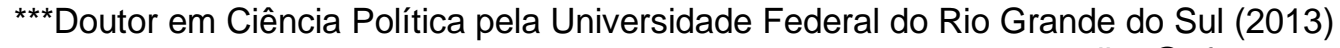
- cesar.a.silva@ufms.com
\end{abstract}

Recebido em 13/03/2020. Aceito para publicação em 17/03/2019.

Versão online publicada em 05/05/2020 (http://seer.ufrgs.br/paraonde)

\section{Resumo:}

A Venezuela durante boa parte do século XX era atrativa e chegou a ser um local de recebimento de migrantes. Não obstante, na segunda década do século XXI teve seu perfil migratório totalmente revertido por conta de uma crise econômica causada pela falência na politica venezuelana. Atualmente, existem mais venezuelanos em outros países a que no território da República Bolivariana Venezuelana. Acredita-se que 48\% permaneceram no Brasil, $23 \%$ retornaram à Venezuela e $29 \%$ seguiram para outros países. A diáspora venezuelana apresenta a uma dinâmica única onde observa-se a fluidez e a imprevisibilidade das rotas, sejam estas marítimas e terrestres. Analisar o dinamismo das migrações venezuelanas não é apenas catalogar as problemáticas e desafios que este grande número de migrantes trará ao Estado brasileiro, mas serve para demonstrar que isto poderá ser a criação de oportunidades para o desenvolvimento econômico e social do Brasil, principalmente dos estados que estão recebendo os fluxos, entretanto observou-se a tentativa por parte do Estado de inviabilizar a integração local que seria a alternativa douradora proposta, optando-se pela interiozação deste grupo que primeiramente foram reconhecidos como acolhidos humanitários temporários, mas essa definição para o ACNUR não seria a mais adequada aos migrantes venezuelanos, pois eles são refugiados que se deslocam devido a grave e generalizada crise econômica. $O$ presente trabalho busca demonstrar a possibilidade da promoção da integração local dos migrantes vulneráveis venezuelanos, consistindo em uma pesquisa interdisciplinar, sob a ótica das Relações Internacionais e do Direito, com a abordagem hipotético-dedutiva através da analise bibliográfica e documental.

Palavras-chave: Venezuelanos. Refugiados. ACNUR. CONARE.

\section{Abstract:}

The Venezuela for much of the twentieth century was attractive and became a place of reception for migrants. Nevertheless, in the second decade of the $21 \mathrm{st}$ century its migratory profile was completely reversed due to an economic crisis 
caused by the failure of Venezuelan politics. There are currently more Venezuelans in other countries than in the territory of the Venezuelan Bolivarian Republic. $48 \%$ remained in Brazil, $23 \%$ returned to Venezuela and $29 \%$ to other countries. The Venezuelan Diaspora presents a unique dynamic where one observes the fluidity and unpredictability of the routes, be they maritime and terrestrial. Analyzing the dynamism of Venezuelan migrations is not only cataloging the problems and challenges that this large number of migrants will bring to the Brazilian state, but also demonstrates that this could be the creation of opportunities for the economic and social development of Brazil, especially those states that are receiving the flows, however there was an attempt by the State to make local integration unfeasible, which would be the proposed golden alternative, opting for the interiozation of this group that were first recognized as temporary humanitarian workers, but this definition for UNHCR would not be the most appropriate for Venezuelan migrants, as they are refugees who move due to the severe and widespread economic crisis. This paper aims to demonstrate the possibility of promoting local integration of vulnerable Venezuelan migrants, consisting of an interdisciplinary research, from the perspective of International Relations and Law, with the hypothetical-deductive approach through bibliographical and documentary analysis.

Key-words: Venezuelans. Refugees. UNHCR. CONARE.

\begin{abstract}
Resumen:
Venezuela durante gran parte del siglo XX fue atractiva y se convirtió en un lugar de recepción para los migrantes. Sin embargo, en la segunda década del siglo XXI su perfil migratorio se revirtió por completo debido a una crisis económica causada por el fracaso de la política venezolana. La diáspora venezolana presenta una dinámica única donde se observa la fluidez e imprevisibilidad de las rutas. El Estado intentó hacer la integración local inviable, que sería la alternativa dorada propuesta, y la interiorización de este grupo se reconoció por primera vez como bienvenida humanitaria temporal, pero esta definición de ACNUR no sería la más apropiada para los migrantes. Venezolanos, ya que son refugiados que se mudan debido a la grave y generalizada crisis económica. El presente trabajo consiste en una investigación interdisciplinaria, desde la perspectiva de las Relaciones Internacionales y el Derecho, con el enfoque hipotético-deductivo a través del análisis bibliográfico y documental.
\end{abstract}

Palabras-clave: Venezolanos; Refugiados. ACNUR. CONARE. Bienvenido.

\title{
1. Introdução
}

A crise política e econômica venezuelana tem sido a causa do aumento da migração venezuelana, uma vez que, segundo dados da Agência da ONU para Refugiados (ACNUR) 5\% (cinco por cento) da população já deixou a Venezuela na tentativa de desvencilhar das violações de direitos fundamentais vividas em decorrência de uma politica econômica caótica. O cenário geopolítico contemporâneo gerou a crise venezuelana discorrendo sobre os fatores que levaram a Venezuela à sua maior diáspora migratória de sua história. Nesse sentido o presente trabalho traz uma análise das migrações venezuelanas quanto a dinâmica do fluxo, direitos e normativas, no intuito de demonstrar que a Venezuela, que no passado foi um país de recebimento de migrantes, tornou-se um país inviabilizado para a permanência de seus nacionais, que se viram obrigados a deixarem o seu país visando sua

ParaOnde!?, Porto Alegre, v.13, n.2, p.90-104, 2020.http://seer.ufrgs.br/paraonde Edição Especial - VII Seminário Internacional de Estudos Fronteriços 
sobrevivência.

O presente artigo está dividido em três seções. A primeira aborda a crise na venezuela e sua dinâmica da migração diante da grave crise política, econômica e humanitária que tem forçado milhares de venezuelanos a se deslocarem para outros países, entre os quais o Brasil. A população vem experimentando uma generalizada ausência de proteção do Estado e violação dos seus direitos fundamentais. Faltam alimentos, remédios e atendimento de saúde. Em virtude disso, milhares de venezuelanos estão deixando seu país para buscar proteção em outros Estados.

Na segunda seção demonstra-se o trabalho do Brasil na interiorização desses migrantes que alivia o fluxo na zona fronteiriça e ao mesmo tempo facilita a eles a retomada do trabalho, a adaptação ao país e o aconchego ao novo lar. O Projeto Acolhida busca o ordenamento de fronteira através da identificação e triagem dos imigrantes que entram no país, bem como a ampliação e requalificação dos abrigos para aqueles que se encontram em situação de vulnerabilidade.

Por fim, na terceira seção apresenta-se a importância do Brasil ter reconhecido a condição de refugiado aos venezuelanos que através desse sistema de refúgio baseado em uma política internacional humanitária busca-se proteger e garantir os direitos humanos a estas pessoas. Desta forma o Governo Brasileiro deve promover a assistência aos refugiados para que vivam de forma saudável, estável e justa.

A análise das implicações que o reconhecimento do status de refugiado aos venezuelanos se faz necessária tendo em vista que é a primeira que o Estado brasileiro a concede em massa como foi neste caso, o presente trabalho consiste em uma pesquisa interdisciplinar, sob a ótica das Relações Internacionais e do Direito, qualitativa pautada em analise bibliográfica e documental, enriquecida com gráficos e quadros esquemáticos produzidos pelas autoras.

\section{A crise na Venezuela e a dinâmica migratória}

A Venezuela moderna formou-se através de crises institucionais que apresentavam a luta interna pelo controle estatal, onde o interesse social da população era menosprezado, reflexos da antiga colonização espanhola nas Américas. A estrutura de controle tributário venezuelana é herança da Coroa Espanhola, assim como a forma de distribuição dos cargos públicos e a estrutura econômica (NEVES, 2010).

Houve poucas mudanças no Estado venezuelano desde a independência, características de países de descolonização, a principal mudança ocorreu na metade do século XIX que foi a oposição dos centralistas com os federalistas, que não modificou o quadro do poder, formando apenas grupos de oposição dentro dos próprios grupos existentes. Existe uma acomodação entre a estrutura econômica e partidárias em detrimento dos interesses do Estado. Criando um Estado fraco com uma população empobrecida com direitos não respeitados, onde suas demandas e

ParaOnde!?, Porto Alegre, v.13, n.2, p.90-104, 2020.http://seer.ufrgs.br/paraonde Edição Especial - VII Seminário Internacional de Estudos Fronteriços 
necessidades não atendidas pelo Estado (NEVES, 2010).

A análise da situação atual venezuelana deve ser feita a partir do modelo do realismo neoclássico (ROSE, 1998) e da teoria da escolha racional (GLASSER, 2010), sendo observado a abordagem da micropolítica da atuação dos presidentes como seus atores que apontam as respostas ao ambiente interno e externo da Venezuela (ROMERO; MIJARES, 2016). A teoria da escolha racional advém da Economia sendo incorporada a Ciência Política através das obras de Downs (1957), Buchanan (1965), Tullock (1965), Stigler (1971) e Olson (1976) que apresentaram a teoria que os agentes sociais estão interessados na maximização da riqueza, de votos, de dimensões mensuráveis em termos de quantidades e sujeitas a constrangimentos de recursos materiais, essas interpretações apesar de diversas levam sempre para a teoria materialista, a qual ocorreu nos governos venezuelanos (FEREJOHN; PASQUINO, 2001).

A ascensão de Nicolás Maduro em 2014 é tida como herdeira sucessora do poder chavista venezuelano, pois estava usando os mesmos discursos populistas de Chávez para vencer uma eleição um tanto quanto questionável, tendo em vista a disparidade de votos e a não presença de observadores internacionais. Lembrando que o partido de Hugo controlava a grande mídia que não apresentou uma paridade na cobertura da campanha do outro candidato. Mesmo diante dessa situação, sua vitória seria como uma máscara aos críticos e aos demais países de que a Venezuela se mantinha democrática (LEVITSKY; ZIBLATT, 2018).

A crise venezuelana agravou-se em 2015 com a derrota do Nicolás Maduro nas eleições parlamentares, sendo este evento o marco da deterioração do governo venezuelano. Com o enfraquecimento das instituições políticas da Venezuela, a o conflito entre o Tribunal Superior de Justiça (TSJ) e o Parlamento Venezuelano, demonstram a profundidade da deterioração, que levou o TSJ a reduzir a oposição parlamentar, anulando as decisões tomadas pelo Parlamento. Esta decisão teve uma enorme repercussão, levando a uma onda de protestos em todo o país, que agravou a tensão entre o governo e a oposição (VAZ, 2017).

Diante desta situação, em 2017, o TSJ tentou novamente investir contra o Parlamento, suspendendo as imunidades dos deputados e assumindo as prerrogativas parlamentares. Neste contexto, a Controladoria da União encontrou oportunidade para caçar os direitos políticos da principal liderança da oposição e também ex-candidato à presidência, Henrique Capriles, porém a Controladoria teve que voltar a atrás nesta decisão diante a comoção popular, que não aceitou a medida (VAZ,2017).

Desta forma, começou a surgir uma demanda oposicionista que pediam que fossem depostos os juízes do TSJ, pela independência do legislativo e pelas eleições gerais urgentemente, pois não reconheciam a permanência de Maduro no poder, uma vez que havia sido derrotado nas eleições. Diante isso, - Presidente Maduro assinou um decreto, que convocava a Assembleia Constituinte para redigir um texto constitucional para promover a reforma do Estado. Este decreto causou grande inconformismo na população que foi às

ParaOnde!?, Porto Alegre, v.13, n.2, p.90-104, 2020.http://seer.ufrgs.br/paraonde Edição Especial - VII Seminário Internacional de Estudos Fronteriços 
ruas protestar, incialmente pacificamente e depois violentamente, o que levou a Organização dos Estados Americanos (OEA) a reunir o Conselho de Ministros para discutirem a Crise Venezuelana que se agravava (VAZ, 2017).

Lembrando que a democracia venezuelana apresentava um projeto hegemônico decorrente da teoria socialista, a qual se utilizava de uma ideologia para justificar o controle estatal internamente, mas internacionalmente se visualizava as teorias neoliberais nas questões da indústria petrolífera (ROMERO; MIJARES, 2016).

A indefinição de uma presidência que se reelegia constantemente controlava a população venezuelana, que se via desamparada economicamente, mesmo com ares de desenvolvimento e crescimento econômico positivos, a instabilidade política causada por sucessivas decisões equivocadas do governo e o fortalecimento do neoliberalismo, que visa unicamente a obtenção de capital sem ter a consciência global, não estabelecendo barreiras, sejam estas ambientais ou sociais, o ser humano é colocado como um agente da economia que deve ser eficiente, gerando lucros, o que diretamente permite que ocorram abusos e o consequente aumento da desigualdade (ROMERO; MIJARES, 2016).

Isto fez com que Nicolas Maduro anunciasse a retirada da Venezuela da OEA pois considerava que esta ação do Conselho de Ministros seria uma tentativa de intervencionista e um exemplo de ingerência indevida aos assuntos internos venezuelanos. Lembrando que a saída da OEA demorará pelo menos dois anos para se consumar, uma vez que existe um débito de dez milhões de dólares da Venezuela com aquele organismo (VAZ, 2017).

Em maio de 2017, os lideres da OEA se reuniram novamente para apresentarem soluções à crise venezuelana, mas não houve nenhuma proposição aprovada por aquele conjunto dos países naquele sentido. Recusaram também a proposta apresentada pelo Brasil, quanto a aplicações de sanções ao governo venezuelano. Lembrando que o país já se encontra suspenso do Bloco do Mercado Comum do Sul (MERCOSUL), desde 2015 devido o descumprimento das obrigações do Protocolo de Adesão, como a centralização e a concentração do poder Executivo, invocando-se a Cláusula Democrática do MERCOSUL (VAZ, 2017).

Esta crise política é acompanhada por uma crise econômica que está tomando dimensões desastrosas em decorrência da queda acentuada da produção e da exportação de petróleo, o desabastecimento dos produtos básicos, pelas taxas de desemprego crescentes, que poderia já ter justificado a decretação do Estado de Exceção e de Emergência Econômica em maio de 2016. É observada também a deterioração da segurança publica da Venezuela. Estes fatores formam um isolamento do governo Maduro, aumentando a apreensão quanto ao crescimento da violência da crise venezuelana (VAZ, 2017).

Anteriormente a Venezuela era um local atrativo para os migrantes provenientes da América do Sul e demais países do mundo, e hoje encontra-se com o perfil migratório revertido em decorrência da crise politica e econômica.

ParaOnde!?, Porto Alegre, v.13, n.2, p.90-104, 2020.http://seer.ufrgs.br/paraonde Edição Especial - VII Seminário Internacional de Estudos Fronteriços 
Existindo um grande um fluxo de venezuelanos dirigindo-se para fora do país, acabando por produzir uma crise migratória na América do Sul (OTERO; TORELLY; RODRIGUES, 2018).

Os fluxos dos cidadãos venezuelanos apresentam uma dinâmica única com uma fluidez e imprevisibilidade de rotas, marítimas e terrestres. Foi visualizado um deslocamento massivo desde o ano de 2015 de venezuelanos para os países vizinhos em decorrência direta do desequilíbrio politico e econômico advindo da politica estatal da Venezuela que era pautada por uma debilidade econômica social. Lembrando que foi em 2015, que ocorreu o agravamento da crise na Venezuela quando o abastecimento dos itens básicos para a sobrevivência da população foi atingido (SILVA,2018). E segundo a OIM, foi registrado o aumento do fluxo migratório de venezuelanos em $27 \% \mathrm{em}$ comparação com o ano de 2015 (OIM, 2018).

\section{Figura 1: Migrantes forçados de todo mundo}

\section{Migrantes forçados pelo mundo em 2018}

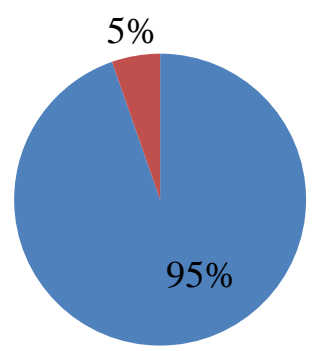

- Total: 70,8 Milhões

- Venezuelanos: 4 Milhões

Fonte: ACNUR, 2019.

O último relatório apresentado pela ACNUR demonstrou que os migrantes forçados já somam 70,8 milhões de pessoas que deixaram seus países diante a impossibilidade de sobrevivência em seus países de origem, e isto soa como um alerta para o aumento das violações de direitos, das crises políticas e econômicas ao redor do mundo. Neste número pode ser visualizado que os venezuelanos já somavam em 2019 o montante de 4 milhões de deslocados, desta formam representando $5 \%$ (cinco por cento) do número de migrantes forçados (ACNUR,2019).

Figura 2: Dados sobre o fluxo migratório venezuelano

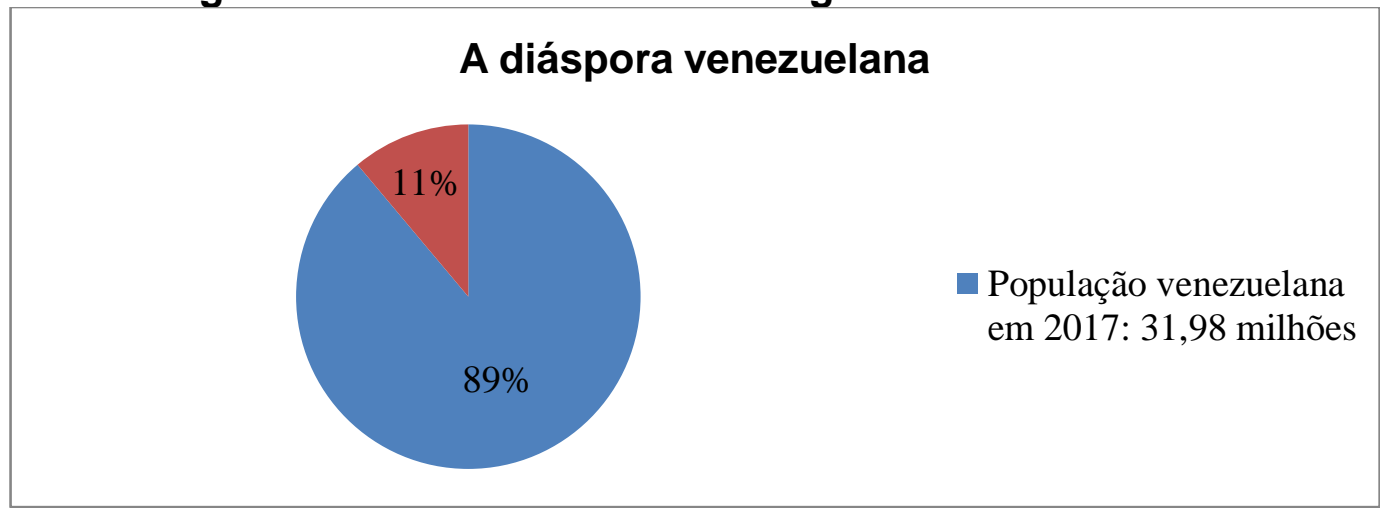

Fonte: BANCO MUNDIAL, 2017 e ACNUR, 2019.

ParaOnde!?, Porto Alegre, v.13, n.2, p.90-104, 2020.http://seer.ufrgs.br/paraonde Edição Especial - VII Seminário Internacional de Estudos Fronteriços 
Diante destes números, observa-se a existência de uma diáspora venezuelana, uma vez que diáspora significa dispersão de povos, por motivos políticos ou religiosos, pois o número de deslocados já representam $11 \%$ (onze por cento) da população total da Venezuela, que segundo o ultimo senso realizado pelo Banco Mundial totalizava 31,98 (trinta e um, e noventa e oito) milhões de pessoas. Observa-se então que o caso venezuelano, que em 4 anos já alcançou a marca de 4 milhões de pessoas deslocadas, poderá se tornar uma crise migratória maior que a própria crise síria devida a velocidade e o crescimento acelerado de venezuelanos que estão deixando o país (ACNUR,2019). Este fluxo afetou a realidade de três países transfronteiriços com a Venezuela, são estes o Brasil, a Colômbia e a Guiana.

A rota mais procurada pelos venezuelanos é para a Colômbia, principalmente pelas semelhanças socioculturais que proporcionaria uma integração social efetiva e também da facilidade de ingresso devida a grande quantidade de cidades gêmeas, da infraestrutura rodoviária, sendo para 0 trânsito ou para destino final. Entretanto, observa-se atualmente 0 deslocamento massivo para outros países sul-americanos, estes como o Brasil, Equador, Chile e Peru, visualizam-se também venezuelanos se deslocando para os países da América Central, Estados Unidos e Europa (OTERO; TORELLY; RODRIGUES, 2018).

Para este caso específico, será analisada apenas a questão dos deslocamentos terrestres para o Brasil, mesmo sendo uma das rotas menos atrativas aos venezuelanos por conta da falta de semelhanças culturais e da burocracia do Estado Brasileiro. No Brasil a principal rota de entrada é através das fronteiras terrestres da região norte, em especial a do estado de Roraima e segundo registros da Policia Federal, coletados até outubro de 2018, os venezuelanos já somavam 88.965 mil, destes 65.621 mil venezuelanos solicitaram refúgio e 23.444 protocolaram pedidos de residência temporária, existe uma estimativa de um fluxo diário de 400 a 500 venezuelanos cruzam a fronteira (OTERO; TORELLY; RODRIGUES, 2018).

Destes acredita-se que $48 \%$ permaneceram no Brasil, $23 \%$ retornaram à Venezuela e 29\% seguiram para outros países. Grande parte dos venezuelanos que estão se deslocando são de origem indígena, em especial dos grupos étnicos E'ñepá e Warao, fator que dificulta ainda mais a integração deste grupo, vez que a maioria fala apenas a língua nativa, fazendo que ocorra certa marginalização e exclusão deste grupo (OTERO; TORELLY; RODRIGUES, 2018).

A OIM estipula o aumento do fluxo migratório venezuelano devido os atuais desenvolvimentos políticos econômicos no país que agravou a situação interna na Venezuela, o acesso à saúde e aos alimentos são inexistentes, as taxas inflacionárias estão nas alturas e a polarização da política está cada dia mais visível, tornando inviável a vida naquele país. $E$ por isso que se faz necessário o fortalecimento das estratégias de acolhimento, determinando uma assistência direta aos migrantes e sua integração socioeconômica no país de recebimento (SAMPAIO; SILVA, 2018).

Analisar o dinamismo das migrações venezuelanas não é apenas

ParaOnde!?, Porto Alegre, v.13, n.2, p.90-104, 2020.http://seer.ufrgs.br/paraonde Edição Especial - VII Seminário Internacional de Estudos Fronteriços 
catalogar as problemáticas e desafios que este grande número de migrantes trará ao Estado brasileiro, mas serve para demonstrar que isto poderá ser a criação de oportunidades para o desenvolvimento econômico e social do Brasil, principalmente dos estados que estão recebendo os fluxos, entretanto observou-se a tentativa por parte do Estado de inviabilizar a integração local que seria a alternativa douradora proposta, optando-se pela interiorização deste grupo promovendo o acolhimento humanitário temporário. E é neste ponto que se questiona a efetividade deste programa vez que se faz existente uma certa descoordenação dos estados que estão recebendo os venezuelanos por meio deste programa (SAMPAIO; SILVA, 2018).

\section{A interiorização dos migrantes venezuelanos: projeto acolhida}

A entrada de um número cada vez maior de imigrantes trouxe desafios também para o abrigamento dessas pessoas. A entrada de imigrantes no Brasil, provenientes da Venezuela, sempre foi uma realidade. Porém, em 2015, o fluxo começou a aumentar consideravelmente. Em 2016, a prefeitura de Boa Vista solicitou uma reunião no Gabinete da Casa Civil da Presidência da República e alertou sobre o início de uma crise no Estado de Roraima. Com a intensificação do fluxo de imigrantes no final de 2017, o Presidente da República decidiu atuar mais diretamente no atendimento humanitário aos venezuelanos (EGAS, 2018).

A quantidade e as condições desses refugiados que estão adentrando no País, bem como a pressão internacional da ONU no sentido de se dar refúgio aos imigrantes, influenciaram no sentido de o Governo brasileiro mudar as normas internas de imigração vigentes, facilitando a recepção e o amparo aos imigrantes. Diante desse cenário, em fevereiro de 2018, o Presidente da República, Michel Temer, decidiu assinar medidas provisórias e decretos, que viabilizaram a missão em favor dos imigrantes venezuelanos em situação de vulnerabilidade no Estado de Roraima, devido à crise política, institucional e socioeconômica vivida pela Bolívia e Venezuela.

A Medida Provisória $n^{\circ}$ 820, de 15 de fevereiro de 2018 estabeleceu medidas de assistência para acolhimento das pessoas em situação de vulnerabilidade decorrente do fluxo migratório, reconhecendo tal situação como uma crise humanitária de caráter emergencial, e criou o Comitê Federal de Assistência Emergencial como instância de governança intersetorial das ações e iniciativas sobre o tema (BRASIL, 2018).

O Decreto $n^{\circ}$ 9.286, de 15 de fevereiro de 2018 definiu a composição, as competências e as normas de funcionamento desse Comitê e o Decreto no 9.285, de 15 de fevereiro de 2018 reconheceu a situação de vulnerabilidade decorrente de fluxo migratório para o Estado de Roraima. Ainda em fevereiro, - Comitê Federal indicou o General de Brigada Eduardo Pazuello como Coordenador Operacional no território (Resolução no 1, de 21 de fevereiro de 2018), que elaborou um plano operacional para assistência emergencial aos imigrantes, com o objetivo de ordenar a fronteira brasileira com a Venezuela e ampliar e qualificar os abrigos para imigrantes. Em março de 2018, a Medida Provisória no 823 abriu crédito extraordinário no valor de $R \$ 190$ milhões, em

ParaOnde!?, Porto Alegre, v.13, n.2, p.90-104, 2020.http://seer.ufrgs.br/paraonde Edição Especial - VII Seminário Internacional de Estudos Fronteriços 
favor do Ministério da Defesa, para financiamento do plano operacional e outras ações de assistência emergencial aos imigrantes (BRASIL, 2018).

As Resoluções no 2, 3 e 4 do Comitê Federal instituíram, respectivamente, o Subcomitê Federal para Interiorização dos Imigrantes que se encontram no Estado de Roraima; Subcomitê Federal para Recepção, Identificação e Triagem dos Imigrantes; e o Subcomitê Federal para Ações de Saúde aos Imigrantes. Dessa forma, foi estabelecida uma estrutura de governança, no âmbito federal, das ações de assistência aos venezuelanos (BRASIL, 2018).

Figura 3: Federalização das migrações

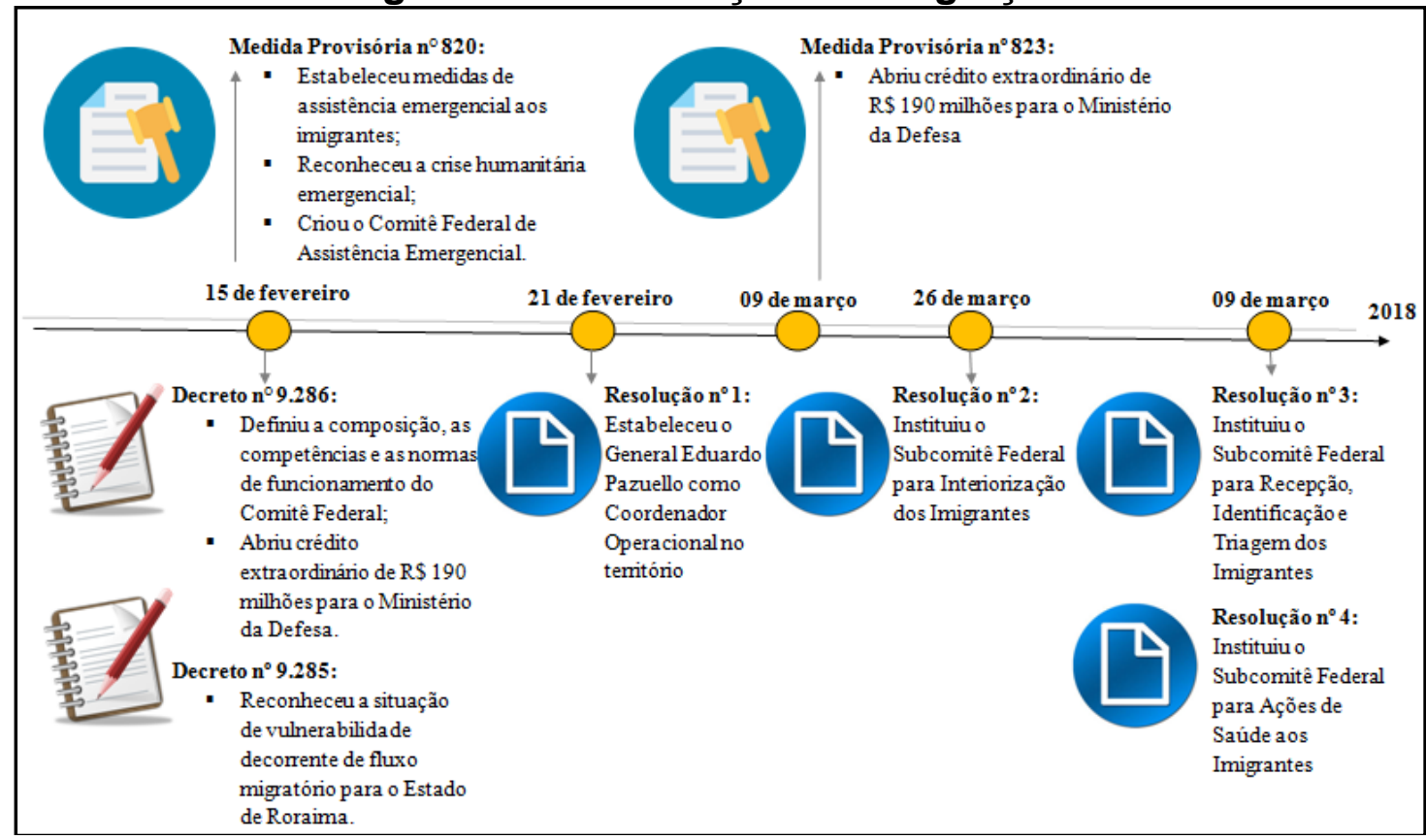

Autora: Nathália Oliveira, 2019.

Desse modo, foi criada a Operação Acolhida, em cujo contexto foi estabelecida a Força-Tarefa Logística Humanitária para o Estado de Roraima. A Operação é conjunta, interagências e de natureza humanitária, envolvendo as Forças Armadas e vários órgãos da esfera federal, estadual e municipal, além de agências internacionais e organizações não governamentais.

A Operação prevê o ordenamento de fronteira, por meio da montagem de estrutura que permita o controle, identificação e triagem dos imigrantes que entram no país na fronteira brasileira com a Venezuela em Roraima, e a ampliação e requalificação dos abrigos para imigrantes em situação de vulnerabilidade (EGAS, 2018).

A interiorização é a estratégia que desloca imigrantes venezuelanos que desejam ir para outros estados brasileiros, com o apoio do Governo Federal. O objetivo consiste em oferecer oportunidades de inserção socioeconômica. Segundo o relatório da OIM de maio de 2019, já foram beneficiados cerca de 8.295 mil venezuelanos. A missão é cooperar com os governos federal, estadual e municipal, com as medidas de assistência emergencial para acolhimento de imigrantes provenientes da Venezuela, que se encontram em

ParaOnde!?, Porto Alegre, v.13, n.2, p.90-104, 2020.http://seer.ufrgs.br/paraonde Edição Especial - VII Seminário Internacional de Estudos Fronteriços 
situação de vulnerabilidade (BRASIL, 2018). De acordo com informações colhidas do Governo Federal em 2018 através da interiorização inúmeras pessoas foram abrigadas. Observa-se:

\section{Figura 4: Interiorização no ano de 2018}

\begin{tabular}{|c|c|c|}
\hline Dia & Nr imigrantes & Cidade destino \\
\hline 05 ABR & 104 & São Paulo \\
\hline \multirow{2}{*}{06 ABR } & 95 & São Paulo \\
\hline & 66 & Cuiabá \\
\hline \multirow{2}{*}{05 MAIO } & 69 & São Paulo \\
\hline & 164 & Manaus \\
\hline 15 MAIO & 29 & Cuiabá \\
\hline TOTAL & \multicolumn{2}{|c|}{527} \\
\hline Dia & Nr imigrantes & Cidade destino \\
\hline \multirow{3}{*}{03 JUL } & 70 & Igarassú-PE \\
\hline & 45 & João Pessoa \\
\hline & 70 & Rio de Janeiro \\
\hline \multirow{3}{*}{09 JUL } & 20 & Cuiabá \\
\hline & 50 & Goioerê-PR \\
\hline & 10 & São Paulo \\
\hline XX JUL & 30 & Manaus \\
\hline TOTAL & \multicolumn{2}{|c|}{295} \\
\hline
\end{tabular}

Fonte: BRASIL, 2018.

Desse modo, para o cumprimento desse objetivo, é realizado apoio logístico em transporte, alimentação e saúde, bem como suporte para o processo de interiorização. Além disso, trabalham-se triagem, identificação, imunização, construção, recuperação e ampliação de abrigos (BRASIL, 2018).

\section{Do reconhecimento da condição de refugiado aos venezuelanos no Brasil, e suas implicações}

Para a ACNUR, o refugiado é todo aquele que se desloca de maneira forçada diante um grau elevado de vulnerabilidade social e econômica que atinge a proteção dos direitos fundamentais, que permite a ocorrência de violações de direito ou ainda o temor de sofrer perseguições, impossibilitando a sobrevivência em seu país de origem, sendo esta condição que o diferencia do migrante internacional, que se deslocou por várias outras razões combinadas principalmente a vontade econômica, tendo a possiblidade de regresso em segurança ao seu país de origem a qualquer momento (ACNUR, 2018).

Já para o ordenamento jurídico brasileiro, na Lei № 9.474 de 1997, o refugiado é aquele que se desloca diante de temores de perseguições fundadas, sejam estes por questões étnicas, nacionais, grupos, opiniões politicas, que o impulsionou a se deslocar de seu país de origem uma vez que não é possível a proteção de seus direitos, sendo reconhecido também aquele que não dispõe de nacionalidade e está fora do país de residência habitual, não podendo regressar, e por fim, é reconhecido também aquele que se

ParaOnde!?, Porto Alegre, v.13, n.2, p.90-104, 2020.http://seer.ufrgs.br/paraonde Edição Especial - VII Seminário Internacional de Estudos Fronteriços 
deslocou de seu país de origem devido a grave e generalizada violação dos direitos humanos e foi obrigado a buscar refúgio em outro Estado (BRASIL, 1997).

Neste ponto, deve ser analisado que os venezuelanos em um primeiro momento para o governo brasileiro foram tratados como uma questão migratória voltada à segurança, sendo reconhecidos como acolhidos humanitários (SAMPAIO; SILVA, 2018), uma vez que não se reconhecia a grave e generalizada violação de direitos fundamentais, o que para o ACNUR foi um erro pois é visível a impossibilidade de sobrevivência na Venezuela ou tão pouco o retorno em segurança a qualquer momento. Neste sentido, no dia 19 de julho de 2019, o CONARE visando acelerar a regularização dos venezuelanos no Brasil, resolveu reconhecer a existência da grave e generalizada violação dos direitos dos venezuelanos, o que permitiu o reconhecimento da condição de refugiado aos venezuelanos.

Existem cerca de 4 milhões de refugiados e migrantes venezuelanos em todo o mundo, sendo que a grande maioria está na América Latina e Caribe, consequência do agravamento da situação caótica da política, da economia e do sistema de proteção dos direitos humanos na Venezuela. Assim, o ACNUR declara que os venezuelanos que estão se deslocando do país necessitam da proteção como refugiados reconhecidos (ACNUR, 2019).

No caso do Brasil, o país apresenta um sistema de refúgio que está baseado em uma política internacional humanitária onde a diplomacia brasileira busca a proteção e promoção dos direitos humanos. O país anteriormente assumia a liderança regional diante as demandas internacionais de cooperação e proteção aos refugiados, se dispondo para prevenir conflitos, construção da paz, promovendo ações para integrar socialmente os imigrantes, em especial os que foram reconhecidos como refugiados, através da via grociana das relações internacionais com a opção do multilateralismo do direito internacional (LAFER,2001).

No processo para reconhecimento da condição de refugiado no Brasil, a pessoa solicitante de refúgio deverá passar, direta e indiretamente, por quatro órgãos, são eles: CONARE, ACNUR, Cáritas e Polícia Federal, pois a cada um desses desempenha a tarefa de promover o reconhecimento do refugio dentro do Brasil, conforme os artigos $7^{\circ}$ e $8^{\circ}$ da Lei $n^{\circ} 9.474$ de 1997:

\begin{abstract}
Art. 7‥ O estrangeiro que chegar ao território nacional poderá expressar sua vontade de solicitar reconhecimento como refugiado a qualquer autoridade migratória que se encontre na fronteira, a qual Ihe proporcionará as informações necessárias quanto ao procedimento cabível.

$\S 1$ 으 Em hipótese alguma será efetuada sua deportação para fronteira de território em que sua vida ou liberdade esteja ameaçada, em virtude de raça, religião, nacionalidade, grupo social ou opinião política.

§ 2응 $\mathrm{O}$ benefício previsto neste artigo não poderá ser invocado por refugiado considerado perigoso para a segurança do Brasil.

Art. $8^{\circ} \mathrm{O}$ ingresso irregular no território nacional não constitui impedimento para o estrangeiro solicitar refúgio às autoridades competentes.
\end{abstract}

ParaOnde!?, Porto Alegre, v.13, n.2, p.90-104, 2020.http://seer.ufrgs.br/paraonde Edição Especial - VII Seminário Internacional de Estudos Fronteriços 
Neste sentido vale frisar que a proteção aos refugiados e assimilados no Brasil está basilada na Constituição Federal, onde é determinado como dever do Estado Brasileiro realizar a integração do refugiado através da tomada de providências através de programas sociais para que estes tenham condições para exercer sua cidadania e vivendo dignamente sem sofrerem nenhuma forma de discriminação em decorrência de sua origem, cultura ou língua, sendo este objetivo previsto no artigo $3^{\circ}$ da Constituição (LAFER,2001):

Art. $3^{\circ}$. Constituem objetivos fundamentais da República Federativa do Brasil:

I- construir uma sociedade livre, justa e solidária; II - garantir o desenvolvimento nacional;

III- erradicar a pobreza e a marginalização e reduzir as desigualdades sociais e regionais;

IV- promover o bem de todos, sem preconceitos de origem, raça, sexo, cor, idade e quaisquer outras formas de discriminação (BRASIL, 1988).

Então, o refúgio é um direito fundamental em que os direitos humanos voltados aos refugiados e solicitantes de refúgio devem prevalecer através de uma integração social nos temos do inciso II, IX e X do artigo 4ํ da Constituição federal:

Art. $4^{\circ}$. A República Federativa do Brasil rege-se nas suas relações internacionais pelos seguintes princípios:

II - prevalência dos direitos humanos;

IX- cooperação entre os povos para o progresso da humanidade;

X-concessão de asilo político (BRASIL,1988).

Atualmente os direitos que os refugiados dispõem: são a regulamentação de sua situação com o reconhecimento da condição de refúgio, a vedação de ser deportado ao seu país de origem onde seus direitos fundamentais estão sendo mitigados. Lembrando que é dever do Estado não ignorar a fragilidade psicológica e social que os refugiados apresentam, devendo analisar e conceder rapidamente positivamente a solicitação de refugio, a fim de que não ocorram descasos aos direitos humanos a eles inerentes (ACNUR,2019).

Desta forma deve promover a assistência para que estes que estão vivendo no país vivam de forma saudável, estável e justa, podendo obter uma vaga de emprego com auxilio de assistentes sociais, sendo também a estes garantido vagas em escolas publicas, creches e universidades, respeitado a dignidade humana que é o um dos superprincípios constitucionais que norteiam um Estado Democrático de Direito (ANDRADE; RAMINA,2018).

A concessão de vistos temporários para a acolhida humanitária também é um dos principais direitos que os refugiados dispõe, e que atualmente foi institucionalizado com o advento da nova legislação de migração, a Lei 13.445/2017. Esta nova legislação simboliza um grande avanço para proteção dos direitos dos refugiados e assimilados, sendo seu principio base a não discriminação em razão de critérios ou de procedimentos pelos quais a pessoa foi admitida em território nacional (ANDRADE; RAMINA,2018).

ParaOnde!?, Porto Alegre, v.13, n.2, p.90-104, 2020.http://seer.ufrgs.br/paraonde Edição Especial - VII Seminário Internacional de Estudos Fronteriços 
Portanto, ressalta-se a importância e necessidade de desenvolver ações e atividades que contribuam para que a sociedade tenha uma percepção realista e positiva da migração, percebendo que não se trata de um problema ou de uma catástrofe, mas, sim, de um fato social, uma grande oportunidade para o desenvolvimento, a colaboração recíproca, a acolhida humanitária e o progresso social.

\section{Considerações finais}

A crise política venezuelana modificou o quadro migratório do país que antes era visto como atrativo para o recebimento de migrantes de todo mundo, hoje observa, segundo dados da ACNUR, mais de 5\% (cinco por cento) de sua população se deslocando para países vizinhos com o intuito de desvencilhar das agressões de direitos fundamentais por parte do Estado.

Diante este quadro, os países fronteiriços viram a diáspora venezuelana modificar a realidade das fronteiras que passaram a receber fluxos jamais vistos de venezuelanos, causando um impacto imediato do quadro migratório, e diante desta situação, o Brasil (o Estado analisado neste trabalho), viu a necessidade de promover algumas estratégias para o recebimento destes migrantes, que a principio eram vistos como acolhidos humanitários, para evitar a formação de um campo de refugiados ou até a promoção da integração local na região de fronteira, extremamente carente de recursos e que estava sofrendo impactos negativos sociais e econômicos.

E desta forma foi idealizado o projeto acolhida aos venezuelanos, com o ACNUR sempre entendendo a necessidade de promover a proteção de refugiado a estes migrantes, porém o Brasil apenas reconheceu esta proteção através de uma decisão do CONARE em meados do mês de junho de 2019, diante esta decisão observa-se a necessidade de apresentar as implicações que este reconhecimento apresenta e foi este ponto que este artigo comprometeu-se apresentar.

\section{Referências}

ANDRADE, Varelia Pereira de; RAMINA, Larissa. Refúgio e dignidade da pessoa humana: breves considerações. In: ANNONI, Danielle (Org.). DIREITO INTERNACIONAL DOS REFUGIADOS E O BRASIL. Curitiba: Gedai/ufpr, 2018. p. 29-40.

ACNUR. Perguntas e respostas. $2019 . \quad$ Disponível em: $<$ https://www.acnur.org/portugues/dados-sobre-refugio/perguntas-erespostas/\#direitos>. Acesso em: 10 jul. 2019.

mundo. 2019.

. Número de refugiados e migrantes da Venezuela no <https://www.acnur.org/portugues/2019/02/25/numero-de-refugiados-emigrantes-da-venezuela-no-mundo-atinge-34-milhoes/>. Acesso em: 20 jul. 2019.

ParaOnde!?, Porto Alegre, v.13, n.2, p.90-104, 2020.http://seer.ufrgs.br/paraonde Edição Especial - VII Seminário Internacional de Estudos Fronteriços 
Maioria das pessoas que foge da Venezuela necessita de <https://www.acnur.org/portugues/2019/05/21/maioria-das-pessoas-que-fogeda-venezuela-necessita-de-protecao-internacional-para-refugiados/>. Acesso em: 15 jul. 2019.

BRASIL. Comitê de Assistência Emergencial. Relatório Trimestral. Disponível em:< http://www.casacivil.gov.br/operacaoacolhida/documentos/20180621_relatorio-trimestral-final-consolidado.pdf>. Acesso em 20 de julho de 2019.

BRASIL. Operação Acolhida. Disponível em: <http://portalarquivos2.saude.gov.br/images/pdf/2018/junho/29/1.b-Apres-CelMerces-MS-1.pdf>. 2018. Acesso em 20 de julho de 2019.

EGAS, José. A solidariedade com refugiados começa com todos nós. Disponível em: <https://www.nepo.unicamp.br/publicacoes/livros/mig_venezuelanas/migracoes _venezuelanas.pdf>. Acesso em 20 de julho de 2019.

GONZÁLEZ, Juan Carlos Murillo. A importância da lei brasileira e suas contribuições regionais. In: BARRETO, Luiz Paulo Teles Ferreira (Org.). Refúgio no Brasil: A proteção brasileira aos refugiados e seu impacto nas Américas . 1. ed. Brasília: ACNUR, Ministério da Justiça, 2010. cap 3, p. 56.

LEVITSKY, Steven; ZIBLATT, Daniel. Como as democracias morrem. Rio de Janeiro: Zahar, 2018. 364 p. Tradução de: Renato Aguiar.

NEVES, Rômulo Figueira. Cultura Política e Elementos de Análise da Política Venezuelana. Brasília: FUNAG, 2010. 152 p.

OTERO, Guilherme; TORELLY, Marcelo; RODRIGUES, Yssyassy. A atuação da Organização Internacional para Migrações no Apoio à gestão do Fluxo migratório Venezuelano no Brasil. In: BAENINGER, Rosa; SILVA, João Carlos Jarochinski (Org.). Migrações Venezuelanas. Campinas: Unicamp, 2018. p. 38-44.

OIM, Organização Internacional Para As Migrações. TENDÊNCIAS MIGRATÓRIAS NACIONAIS NA AMÉRICA DO SUL: República Bolivariana da Venezuela. Brasília/df: Escritório Regional da Oim Para A América do Sul, 2018. (Série sistemática de relatórios sobre migração). Análise de Migração do Escritório Regional da OIM para a América do Sul.. Disponível em: $<$ https://robuenosaires.iom.int/sites/default/files/Informes/Tendencias_Migratoria s_Nacionales_en_America_del_Sur_Vzla_Portugues.pdf>. Acesso em: 18 jun. 2019.

SILVA, Sidney Antonio; TORELLY, Marcelo (Org.). Diagnóstico e avaliação da migração indígena da Venezuela para Manaus, Amazonas. Brasília: Organização Internacional para as Migrações (OIM), Agência das Nações Unidas para as Migrações, 2018.

SAMPAIO, Cyntia; SILVA, João Carlos Jarochinski. Complexidade $\mathrm{x}$ Singularidade: A necessidade de Outras soluções douradoras. In:

ParaOnde!?, Porto Alegre, v.13, n.2, p.90-104, 2020.http://seer.ufrgs.br/paraonde Edição Especial - VII Seminário Internacional de Estudos Fronteriços 
BAENINGER, Rosa; SILVA, João Carlos Jarochinski (Org.). Migrações Venezuelanas. Campinas: Unicamp, 2018. p. 391-394.

VAZ, Alcides. A crise venezuelana como fator de instabilidade regional: Perspectivas sobre seu transbordamento nos espaços fronteiriços. Análise Estratégica, no.2, 2017.

ROMERO, Carlos A.; MIJARES, Víctor M.. From Chávez to Maduro: Continuity and Change in Venezuelan Foreign Policy. Contexto Internacional, [s.I.], v. 38, n. $1, \quad$ p.165-201, 17 maio 2016. FapUNIFESP (SciELO). http://dx.doi.org/10.1590/s0102-8529.2016380100005. 